CLINICAL STUDY

\title{
Arrest of atherosclerosis progression after interruption of GH replacement in adults with congenital isolated GH deficiency
}

\author{
Vanessa P Araujo, Manuel H Aguiar-Oliveira, Joselina L M Oliveira, Hertaline M N Rocha, Carla R P Oliveira, \\ Tânia M A Rodrigues, Marco A Nunes, Isabella M P A Britto, Roberto Ximenes, Jose A S Barreto-Filho, \\ Rafael A Meneguz-Moreno, Rossana M C Pereira, Eugênia H O Valença, Luiz A Oliveira-Neto, Taisa A R Vicente, \\ Amanda Blackford $^{1}$ and Roberto Salvatori ${ }^{2}$ \\ Department of Medicine, Federal University of Sergipe, Aracaju 49060-100, Brazil, ${ }^{1}$ Sidney Kimmel Comprehensive Cancer Center and ${ }^{2}$ Division of \\ Endocrinology, Department of Medicine, The Johns Hopkins University School of Medicine, 1830 East Monument Street, Suite 333, Baltimore, Maryland \\ 21287, USA \\ (Correspondence should be addressed to R Salvatori; Email: salvator@jhmi.edu)
}

\begin{abstract}
Objective: GH replacement therapy (GHRT) in adult-onset GH deficiency (AOGHD) reduces carotid intima-media thickness (IMT) and increases myocardial mass, with improvement of systolic and diastolic function. These observations have reinforced the use of GHRT on AOGHD. Conversely, we have previously reported that in adults with lifetime congenital and severe isolated GH deficiency (IGHD) due to a mutation in GHRH receptor gene (GHRHR), a 6-month treatment with depot GH increased carotid IMT, caused the development of atherosclerotic plaques, and an increase in left ventricular mass index (LVMI), posterior wall, and septal thickness and ejection fraction. Such effects persisted 12 months after treatment (12-month washout - 12mo).

Methods: We have studied the cardiovascular status (by echocardiography and carotid ultrasonography) of these subjects 60 months after completion of therapy (60-month washout - 60mo).

Results: Carotid IMT reduced significantly from 12 to $60 \mathrm{mo}$, returning to baseline (pre-therapy) value. The number of individuals with plaques was similar at 12 and $60 \mathrm{mo}$, remaining higher than pretherapy. LVMI, relative posterior wall thickness, and septum thickness did not change between 12 and $60 \mathrm{mo}$, but absolute posterior wall increased from 12 to 60mo. Systolic function, evaluated by ejection fraction and shortening fraction, was reduced at $60 \mathrm{mo}$ in comparison with $12 \mathrm{mo}$ returning to baseline levels. The $E / A$ wave ratio (expression of diastolic function) decreased at $60 \mathrm{mo}$ compared with both $12 \mathrm{mo}$ and baseline.

Conclusions: In adults with lifetime congenital IGHD, the increase in carotid IMT elicited by GHRT was transitory and returned to baseline 5 years after therapy discontinuation. Despite this, the number of subjects with plaques remained stable at $60 \mathrm{mo}$ and higher than at baseline.
\end{abstract}

European Journal of Endocrinology $166977-982$

\section{Introduction}

GH deficiency (GHD) in adults has been associated with increased cardio- and cerebrovascular mortality $(1,2)$. This has been attributed to premature atherosclerosis, possibly due to high levels of total and LDL, C-reactive protein (CRP), and abdominal obesity and insulin resistance (3). Accordingly, increased intima-media thickness (IMT) (4) and impaired cardiac performance have been reported in patients with adult-onset GHD (AOGHD) (5). However, most of this literature is based on the studies on AOGHD of different severities and etiologies, often confounded by surgery or radiation, and other associated pituitary deficiencies with multiple hormonal replacement therapies.

We have reported a large extended pedigree from Itabaianinha County (Northeast Brazil) with $\sim 100$ affected individuals (over several generations) with congenital isolated GHD (IGHD), due to a homozygous null mutation in the splice donor site of intron 1 (c.57+ $1 \mathrm{G}>\mathrm{A}$ ) of the GHRH receptor gene (GHRHR) (6). These individuals have very low serum GH and insulin-like growth factor 1 (IGF1), reduced fat-free mass, increased percentage of fat mass, total and LDL, CRP levels, systolic blood pressure (SBP), and waist:hip ratio. Despite these cardiovascular risk factors, they have no premature atherosclerosis, no insulin resistance, and normal longevity $(7,8,9,10,11)$.

Differently from AOGHD patients, in whom GH replacement therapy (GHRT) improves carotid IMT and cardiac performance (5), we have found that in these adult IGHD individuals, a 6-month treatment with depot GHRT, despite beneficial effects on metabolic 
and body composition parameters, caused worsening of atherosclerosis. We noted an increase in IMT, and in the number of individuals with atherosclerotic plaques (from only one at baseline to five after GH and to fourteen 12 months after completion of therapy), together with an increase in left ventricular mass index, posterior wall, and septum thickness, and a late increase in SBP that persisted at the 12-month washout (12).

The aim of this study was to monitor the status of carotid artery walls, cardiac morphology and function, and blood pressure 60 months after termination of GHRT.

\section{Subjects and methods}

\section{Subjects}

Twenty adult GH-naïve IGHD subjects from Itabaianinha homozygous for the c.57+1G>A GHRHR mutation ( 10 men; age, $46 \pm 14.5$ years; height, $122.1 \pm 7.7 \mathrm{~cm}$; weight, $36.7 \pm 5.4 \mathrm{~kg}$, body mass index (BMI), 24.8 \pm 4.3 ) were previously studied at baseline, after 6 months of bimonthly depot $\mathrm{GH}$ (Nutropin Depot; post-GH), and after 6 and 12 months of washout ( 6 and $12 \mathrm{mo}$ ). The initial and final doses were 0.33 and $0.38 \mathrm{mg} / \mathrm{kg}$ in women and 0.25 and $0.35 \mathrm{mg} / \mathrm{kg}$ in men respectively. This dosing was based on the previous work showing an increase in both $\mathrm{GH}$ and IGF1 lasting 14-17 days in adults after a single 0.25 or $0.5 \mathrm{mg} / \mathrm{kg}$ dose (13). A similar starting dose $(0.3 \mathrm{mg} / \mathrm{kg})$ was used in the only clinical trial that has shown efficacy of this depot GH preparation in adults (14). The average daily dose per body weight was 27.1 and $25 \mu \mathrm{g} / \mathrm{kg}$ per day in women and men respectively. In this study, the cohort was examined at 60-month (60-mo) washout time. One patient died before the 60-mo time point due to respiratory disease (likely pneumonia) without a final autopsy diagnosis. Because of this, the group size was restricted to 19 individuals at the 60-mo time point. Both the Federal University of Sergipe and The Johns Hopkins University institutional review boards approved these studies, and all subjects signed informed consent.

\section{Study protocol}

Anthropometric and blood pressure measurements Height and body weight were measured and BMI was calculated using the formula: weight (kilograms)/height (meters $)^{2}$. BP was registered as the mean value of three measurements after $10 \mathrm{~min}$ in seated position.

Laboratory assessment Total cholesterol, triglycerides, and glucose were measured by the enzymatic Trinder colorimetric test. IGF1 was measured by an immunoradiometric assay, with double extraction and an assay sensitivity of $0.8 \mathrm{ng} / \mathrm{ml}$ (5600; Diagnostic
Systems Laboratories, Inc., Webster, TX, USA). The intra- and interassay variabilities were 2.25 and $2.6 \%$ respectively.

Assessment of carotid IMT Longitudinal ultrasonography scans of the carotid arteries were performed by the same trained observer as described previously (12). Atherosclerotic plaque was defined as a localized thickening $\geq 1.3 \mathrm{~mm}$, which did not uniformly involve the whole carotid with or without flow disturbance (12).

Resting echocardiography Echocardiography studies were performed with a commercial machine (HP-Sonos 5500; Hewlett-Packard Co., Palo Alto, CA, USA) according to the standard procedures. M-mode echocardiography of the left ventricle (LV) was performed according to the American Society of Echocardiography recommendations. Only frames with optimal visualization of interfaces and simultaneously visible septum, $\mathrm{LV}$ internal diameters, and posterior wall were used for calculations. LV mass was calculated and normalized according to body surface area and height. Relative wall thickness was calculated as $(2 \times$ posterior wall thickness)/LV internal radius (12).

\section{Statistical analyses}

Anthropometric measurements, blood pressure, carotid IMT, and resting echocardiography measurements are expressed in mean (s.D.), except IGF1 levels expressed in median (interquartile range).

Because in the original study the maximal effects on BP, IMT, and cardiac morphology were found at $12 \mathrm{mo}$, here we were specifically interested in comparing 60 to $12 \mathrm{mo}$. All measurements at all time points were modeled using linear regression models with generalized estimating equations to account for the correlation between measures within individuals. The contrast between 60 and 12mo was estimated from the model with its corresponding 95\% confidence interval. Analyses were completed using software SPSS/PC 16.0 (SPSS, Inc., Chicago, IL, USA) and R version 2.13.1 (http://www.r-project.org). $P$ values are shown, not adjusted for multiple comparisons.

\section{Results}

Weight, BMI, glucose, total cholesterol, triglycerides, and IGF1 did not change from 12- to 60-mo washout (Table 1). In contrast, IMT reduced from 12 to $60 \mathrm{mo}$ $(P=0.03)$ returning to the baseline values. At $12 \mathrm{mo}$, 14 of 20 individuals had carotid plaques. Subsequently, one more individual presented a plaque, and in another the plaque disappeared. With the death of an individual with a plaque before the 60-mo time point, the number of individuals with plaques was not different at $60 \mathrm{mo}$ $(13 / 19)$ vs at $12 \mathrm{mo}(14 / 20)$. 
Table 1 Blood pressure, laboratory, carotid intima-media thickness and resting echocardiographic data in isolated GH-deficient subjects at baseline $(n=20)$, after 6 months of $\mathrm{GH}(n=20)$, after 12 months (12mo, $n=20)$, and 60 months $(60 \mathrm{mo}, n=19)$ of washout. Values are means (S.D., except for IGF1 levels expressed in median (interquartile range)). Statistics refer to comparison between 12 and $60 \mathrm{mo}$.

\begin{tabular}{|c|c|c|c|c|}
\hline & Baseline & Post-GH & $12 \mathrm{mo}$ & $60 \mathrm{mo}$ \\
\hline Weight $(\mathrm{kg})$ & $37.16(4.85)$ & 36.91 (3.95) & $36.57(4.86)$ & $38.94(5.74)$ \\
\hline $\mathrm{BMI}\left(\mathrm{kg} / \mathrm{m}^{2}\right)$ & $25(4.31)$ & $24.75(3.23)$ & $24.51(3.68)$ & $26.14(4.61)$ \\
\hline Glucose $(\mathrm{mg} / \mathrm{dl})$ & 95.74 (12.63) & $92.11(10.36)$ & $98.68(10.11)$ & $102.56(40.52)$ \\
\hline Cholesterol (mg/dl) & $212.11(53.91)$ & $185.05(37.92)$ & $209.42(50.65)$ & 234.56 (58.59) \\
\hline Triglycerides $(\mathrm{mg} / \mathrm{dl})$ & $159.05(105.11)$ & $129.21(101.52)$ & $140.79(90.91)$ & $129.61(57.74)$ \\
\hline IGF1 (ng/ml) & $1(0)$ & 27 (21.5) & $1(0)$ & $1(0)$ \\
\hline $\mathrm{SBP}(\mathrm{mm} \mathrm{Hg})$ & $119.84(18.09)$ & $129.26(27.06)$ & $134.53(23.92)$ & $121.25(15.22)^{*}$ \\
\hline $\mathrm{DBP}(\mathrm{mm} \mathrm{Hg})$ & $75.32(11.84)$ & $80.53(10.68)$ & $78.63(9.8)$ & $81.56(9.26)$ \\
\hline IMT (mm) & $0.6(0.10)$ & $0.68(0.14)$ & $0.8(0.17)$ & $0.68(0.15)^{\star}$ \\
\hline LVMI $\left(\mathrm{g} / \mathrm{m}^{2}\right)$ & $62.54(16.14)$ & $72.57(15.74)$ & $76.84(15.57)$ & $79.9(17.72)$ \\
\hline RPWT (\%) & $26.79(4.87)$ & $32.55(4.06)$ & $32.3(4.29)$ & $32.8(3.52)$ \\
\hline PWT $(\mathrm{cm})$ & $0.56(0.11)$ & $0.68(0.08)$ & $0.67(0.07)$ & $0.74(0.07)^{\star \star \star}$ \\
\hline EDD (cm) & $4.14(0.24)$ & $4.19(0.34)$ & $4.19(0.43)$ & $4.24(0.38)$ \\
\hline SWT $(\mathrm{cm})$ & $0.6(0.12)$ & $0.73(0.09)$ & $0.68(0.1)$ & $0.72(0.1)$ \\
\hline$E / A$ & $1.36(0.63)$ & $1.32(0.52)$ & $1.24(0.45)$ & $0.88(0.37)^{\star \star}$ \\
\hline$E^{\prime} / A^{\prime}$ & $1.07(0.38)$ & $1.01(0.42)$ & $1.06(0.47)$ & $0.88(0.37)$ \\
\hline $\mathrm{EF}(\%)$ & $0.69(0.05)$ & $0.69(0.03)$ & $0.71(0.04)$ & $0.69(0.04)^{\star}$ \\
\hline SF $(\%)$ & $38.11(3.75)$ & $38.25(2.26)$ & 40.75 (3.48) & $38.65(2.97)^{*}$ \\
\hline
\end{tabular}

SBP, systolic blood pressure; DBP, diastolic blood pressure; IMT, intima-media thickness; LVMI, left ventricle mass index; RPWT, relative posterior wall thickness; PWT, posterior wall thickness; EDD, end diastolic diameter; SWT, septal wall thickness; $E / A, E / A$ ratio; $E^{\prime} / A^{\prime}, E^{\prime} / A^{\prime}$ ratio; $E F$, ejection fraction; SF, shortening fraction. ${ }^{\star} P<0.05 ;{ }^{* \star} P<0.01 ;{ }^{* \star} P<0.001$.

SBP reduced from 12 to $60 \mathrm{mo}(P=0.04)$, returning to the baseline values. Diastolic blood pressure (DBP) did not change from 12 to $60 \mathrm{mo}$, remaining higher at $60 \mathrm{mo}$ in comparison with baseline $(P=0.04)$. Among the parameter of cardiac mass, no significant difference in LV mass index, relative posterior wall thickness, end diastolic diameter, and septum thickness was observed at 60 vs $12 \mathrm{mo}$, but absolute posterior wall increased from 12 to $60 \mathrm{mo},(P<0.001)$. Both the parameters of systolic function (ejection fraction and shortening fraction) were reduced at $60 \mathrm{mo}$ in comparison with $12 \mathrm{mo}(P=0.05$ and 0.04 respectively) and were no different from baseline. Of the parameters of diastolic function $(E / A$ (tissue Doppler-derived diastolic velocities) and $E^{\prime} / A^{\prime}$ wave ratios), only $E / A$ was decreased at $60 \mathrm{mo}$ in comparison with $12 \mathrm{mo}$ $(P=0.006)$, and it was lower than that in baseline value $(P=0.002)$.

\section{Discussion}

Our previous data show that in adult patients with lifetime untreated IGHD, a 6-month treatment with GH has reversible beneficial effects on body composition and metabolic profile. The beneficial effects on body composition and metabolic profile were also demonstrated in children and adolescents together with a good somatic growth response (15). Despite these positive effects, GHRT in IGHD adults caused a progressive increase in IMT, SBP, and in the number of individuals with atherosclerotic carotid plaques (from one to 14) up to 12 months after GHRT completion (12). Now we show that SBP and IMT reduced from 12 to $60 \mathrm{mo}$, both returning to the baseline values, despite 5 and $1 / 2$ years of aging, and despite cholesterol levels at $60 \mathrm{mo}$ being no different from $12 \mathrm{mo}$. Both SBP and IMT reductions (with return to pre-GHRT level) from 12 to 60 mo can be attributed to $\mathrm{GH}$ withdrawal and disappearance of its effect with time.

Our original findings contrasted with several reports of increased arterial wall thickness in untreated AOGHD $(5,16)$, and its reduction caused by GHRT $(17,18)$, and stresses the differences that exist between AOGHD and congenital IGHD. This follow-up study shows that the detrimental effect on carotid IMT is not permanent, similar to the positive effect of GHRT in AOGHD subjects, in whom it increases within 6 months from GH withdrawal (17). We also found that the number of individuals with atherosclerosis plaques did not further increase with longer follow-up, but in one individual the plaque disappeared, showing that despite some conflicting data $(19,20)$, it is possible not only to reduce vascular wall volume but also to decrease plaques' volume as shown with some lipid-lowering agents $(21,22)$. This occurred despite atherogenic conditions, such as abdominal obesity, increased SBP, LDL, and CRP $(8,9,10)$.

The cause(s) of the mirror effect of GHRT and GH withdrawal in our IGHD patients when compared with AOGHD can be only speculated. Our patients have extremely low IGF1 levels throughout life, while AOGHD patients have normal levels until they develop GHD, and their IGF 1 decreases rarely become extreme. IGF1 
has a double influence on the atherosclerotic physiopathology, inducing vasodilatation and promoting atherogenesis (23). It is possible that different degrees and duration of GHD may result in different effects on the vascular wall, with very severe IGF1 deficiency protecting against and milder deficiency accelerating atherosclerosis. Our GHRT depot schedule may have transformed our subjects in a 'partial' AOGHD-like condition, and 60 months of washout brought the atherosclerosis to the indolent rhythm typical of this IGHD cohort. The number of treated individuals is small and it is therefore unlikely that in the future we will be able to determine whether these changes translate in a prevalence of cerebrovascular accidents that is different from the never-treated IGHD subjects from the same cohort.

The reported effects of GH replacement on cardiac performance are conflicting $(24,25)$. A meta-analysis reported an increase in myocardial mass and improvement in systolic and diastolic functions, increase in $\mathrm{LV}$ mass, septal thickness, left ventricular posterior wall thickness, and end diastolic volume caused by GHRT in AOGHD (25). On the other hand, no significant changes have been reported in fractional shortening, left ventricular end systolic diameter, and E/A ratio (25). Our study shows that the increase in all the LV mass parameters caused by GHRT persisted at $60 \mathrm{mo}$, suggesting permanent structural changes and showing that even a relatively short-term GHRT may change cardiac anatomy well beyond the end of therapy. We have found a similar long-term effect on thyroid volume, at least at $12 \mathrm{mo}(26)$, suggesting that both heart and thyroid are very sensitive to GH replacement. This is different from acromegaly patients, in whom control of GH/IGF1 excess is associated with normalization of LV mass and LV dimensions (27). Although the changes in ejection fraction between 60 and $12 \mathrm{mo}$ are probably not clinically relevant, systolic function, in agreement with other studies $(6,17)$, improved with GH therapy and returned to baseline values after 60 months of washout, suggesting a nonanatomically mediated effect of $\mathrm{GH}$ on systolic function.

$E / A$ wave ratio did not change after $\mathrm{GH}$ treatment but decreased at $60 \mathrm{mo}$, in comparison with baseline. E/A wave ratio is more impaired in clinically controlled than in surgically cured acromegaly patients, suggesting that diastolic dysfunction may occur even with subtle excess of GH secretion (27). This worsening during late GHRT washout may be attributed to aging, as it was accompanied by a simultaneous increase in DBP.

Our study has some limitations, particularly related to the possible confounding effects of aging. However, the fact that IMT returns to pre-treatment levels goes against an age effect. Secondly, our data were generated in middle-aged adults with genetic IGHD at a dose of depot GH only used once previously in adults (13). This may have resulted in a relatively high daily dose per body weight, although this is unlikely, as serum nadir
IGF1 never actually normalized throughout the study (12). The depot form may have exposed tissues to constant levels of $\mathrm{GH}$, resembling a mild form of acromegaly. Withdrawal from such treatment could therefore be beneficial and account for some of the cardiovascular variables that are improved after 60-month observation. Recently, it has been reported that GH treatment in very low dose (approximately onetenth of the one we have used) enhances insulin sensitivity with no apparent effects on body composition, lipolysis, and other surrogate cardiovascular risk markers in adults with severe acquired GHD (28). Lowdose short-acting GH regimen could have different vascular effects. Finally, we had found that HDL had increased post-GH but had reduced at $12 \mathrm{mo}$ to a lower level than baseline. Regrettably, we do not have fractionated cholesterol data at $60 \mathrm{mo}$ to determine whether changes in HDL may have contributed to reversal or arrest of the negative effects of GHRHT.

In conclusion, in adults with congenital, lifetime severe IGHD, long-term observation after withdrawal of a 6-month sub-maximal GHRT shows arrest of progression of atherosclerosis and reversal of carotid IMT increase but not of plaques. Similarly, heart function benefits are reversible. Conversely, changes in heart anatomy are not reversible.

\section{Declaration of interest}

The authors declare that there is no conflict of interest that could be perceived as prejudicing the impartiality of the research reported.

\section{Funding}

This work was supported by NIH grant 1 R01 DK065718 and a grant from the Genentech Center for Clinical Research in Endocrinology (both to R Salvatori). Clinicaltrial.gov identifier NCT00149708.

\section{Acknowledgements}

The authors thank the 'Associação do Crescimento Físico e Humano de Itabaianinha' and 'Clinica e Hospital São Lucas Aracaju- Sergipe' for their assistance.

\section{References}

1 Bengtsson BA. Untreated growth hormone deficiency explains premature mortality in patients with hypopituitarism. Growth Hormone \& IGF Research 19988 (Suppl A) 77-80. (doi:10.1016/ S1096-6374(98)80014-2)

2 Rosen T \& Bengtsson BA. Premature mortality due to cardiovascular disease in hypopituitarism. Lancet 1990336 285-288. (doi:10.1016/0140-6736(90)91812-0)

3 Gola M, Bonadonna S, Doga M \& Giustina A. Clinical review: growth hormone and cardiovascular risk factors. Journal of Clinical Endocrinology and Metabolism 200590 1864-1870. (doi:10.1210/jc.2004-0545)

4 Markussis V, Beshyah SA, Fisher C, Sharp P, Nicolaides AN \& Johnston DG. Detection of premature atherosclerosis by high- 
resolution ultrasonography in symptom-free hypopituitary adults. Lancet 1992340 1188-1192. (doi:10.1016/0140-6736(92) 92892-J)

5 Colao A, di Somma C, Cuocolo A, Spinelli L, Tedesco N, Pivonello R, Bonaduce D, Salvatore M \& Lombardi G. Improved cardiovascular risk factors and cardiac performance after 12 months of growth hormone $(\mathrm{GH})$ replacement in young adult patients with GH deficiency. Journal of Clinical Endocrinology and Metabolism 200186 1874-1881. (doi:10.1210/jc.86.5.1874)

6 Salvatori R, Hayashida CH, Aguiar-Oliveira MH, Phillips JA III, Souza AH, Gondo RG, Toledo SPA, Conceição MM, Prince M, Baumann G, Maeshwari H \& Levine MA. Familial dwarfism due to a novel mutation in the growth hormone-releasing hormone receptor gene. Journal of Clinical Endocrinology and Metabolism 199984 917-923. (doi:10.1210/jc.84.3.917)

7 Aguiar-Oliveira MH, Oliveira FT, Pereira RM, Oliveira CR, Blackford A, Valenca EH, Santos EG, Gois-Junior MB, MeneguzMoreno RA, Araujo VP, Oliveira-Neto LA, Almeida RP, Santos MA, Farias NT, Silveira DC, Cabral GW, Calazans FR, Seabra JD, Lopes TF, Rodrigues EO, Porto LA, Oliveira IP, Melo EV, Martari M \& Salvatori R. Longevity in untreated congenital growth hormone deficiency due to a homozygous mutation in the GHRH receptor gene. Journal of Clinical Endocrinology and Metabolism 201095 714-721. (doi:10.1210/jc.2009-1879)

8 Oliveira CR, Salvatori R, Meneguz-Moreno RA, AguiarOliveira MH, Pereira RM, Valença EH, Araujo VP, Farias NT, Silveira DC, Vieira JG \& Barreto-Filho JA. Adipokine profile and urinary albumin excretion in isolated growth hormone deficiency. Journal of Clinical Endocrinology and Metabolism 2010 95 693-698. (doi:10.1210/jc.2009-1919)

9 Barreto-Filho JA, Alcantara MR, Salvatori R, Azevedo M, Barreto M, Sousa AC, Bastos VPC, Souza AHO, Pereira RMC, Clayton PE, Gill MS \& Aguiar-Oliveira MH. Familial isolated growth hormone deficiency is associated with increased systolic blood pressure, central obesity, and dyslipidemia. Journal of Clinical Endocrinology and Metabolism 200287 2018-2023. (doi:10.1210/jc.87.5.2018)

10 Menezes Oliveira JL, Marques-Santos C, Barreto-Filho JA, Ximenes Filho R, Valadão de Oliveira Britto A, Oliveira Souza AH, Prado CM, Pereira Oliveira CR, Pereira RMC, de Almeida Ribeiro Vicente T, Teles Farias C, Aguiar-Oliveira MH \& Salvatori R. Lack of evidence of premature atherosclerosis in untreated severe isolated growth hormone (GH) deficiency due to a GH releasing hormone receptor mutation. Journal of Clinical Endocrinology and Metabolism 200691 2093-2099. (doi:10.1210/jc.2005-2571)

11 Oliveira CR, Salvatori R, Barreto-Filho JA, Rocha IE, Mari A, Pereira RM, Campos VC, Menezes M, Gomes E, MeneguzMoreno RA, Araújo VP, Leite NT, Nascimento-Junior AC, Farias MI, Vicente TA, Araújo RD, Melo EV \& AguiarOliveira MH. Insulin sensitivity and $\beta$ cell function. Journal of Clinical Endocrinology and Metabolism 201297 1013-1019.

12 Oliveira JL, Aguiar-Oliveira MH, D'Oliveira A Jr, Pereira RM, Oliveira CR, Farias CT, Barreto-Filho JA, Anjos-Andrade FD, Marques-Santos C, Nascimento-Junior AC, Alves EO, Oliveira FT, Campos VC, Ximenes R, Blackford A, Parmigiani G \& Salvatori R. Congenital growth hormone $(\mathrm{GH})$ deficiency and atherosclerosis: effects of $\mathrm{GH}$ replacement in $\mathrm{GH}$-naïve adults. Journal of Clinical Endocrinology and Metabolism 200792 4664-4670. (doi:10. 1210/jc.2007-1636)

13 Cook DM, Biller BMK, Vance ML, Hoffman AR, Phillips LD, Ford KM, Benziger DP, Illeperuma A, Blethen SL, Attie KM, Dao LN, Reimann JD \& Fielder PJ. The pharmacokinetic and pharmacodynamic characteristics of a long-acting growth hormone $(\mathrm{GH})$ preparation (Nutropin Depot) in GH deficient adults. Journal of Clinical Endocrinology and Metabolism $2002 \mathbf{8 7}$ 4508-4514. (doi:10.1210/jc.2002-020480)

14 Hoffman AR, Biller BMK, Cook D, Baptista J, Silverman BL, Dao L, Attie KM, Fielder P, Maneatis T, Lippe B \& Genentech Adult Growth Hormone Deficiency Study Group. Efficacy of a long-acting growth hormone $(\mathrm{GH})$ preparation in patients with adult GH deficiency. Journal of Clinical Endocrinology and Metabolism 2005 90 6431-6440. (doi:10.1210/jc.2005-0928)

15 Gleeson H, Barreto ES, Salvatori R, Costa L, Oliveira CRP, Pereira RMC, Clayton P \& Aguiar-Oliveira MH. Metabolic effects of growth hormone $(\mathrm{GH})$ replacement in children and adolescents with severe isolated GH deficiency due to a GHRH receptor mutation. Clinical Endocrinology 200766 466-474.

16 Murray RD, Wieringa G, Lawrence JA, Adams JE \& Shalet SM. Partial growth hormone deficiency is associated with an adverse cardiovascular risk profile and increased carotid intima-medial thickness. Clinical Endocrinology 201073 508-515.

17 Colao A, Di Somma C, Rota F, Pivonello R, Savanelli MC, Spezia S \& Lombardi G. Short-term effect of growth hormone (GH) treatment or deprivation on cardiovascular risk parameters and intimamedia thickness at carotid arteries in patients with severe $\mathrm{GH}$ deficiency. Journal of Clinical Endocrinology and Metabolism 2005 90 2056-2062. (doi:10.1210/jc.2004-2247)

18 Colao A, Di Somma C, Cuocolo A, Spinelli L, Acampa W, Spezia S, Rota F, Savanelli MC \& Lombardi G. Does a gender-related effect of growth hormone $(\mathrm{GH})$ replacement exist on cardiovascular risk factors, cardiac morphology, and performance and atherosclerosis? Results of a two-year open, prospective study in young adult men and women with severe GH deficiency. Journal of Clinical Endocrinology and Metabolism 200590 5146-5155. (doi:10. 1210/jc.2005-0597)

19 Nissen SE. Halting the progression of atherosclerosis with intensive lipid lowering: results from the Reversal of Atherosclerosis with Aggressive Lipid Lowering (REVERSAL) trial. American Journal of Medicine 2005118 (Suppl 12A) 22-27. (doi:10.1016/j.amjmed.2005.09.020)

20 Shai I, Spence JD, Schwarzfuchs D, Henkin Y, Parraga G, Rudich A, Fenster A, Mallet C, Liel-Cohen N, Tirosh A, Bolotin A, Thiery J, Fiedler GM, Blüher M, Stumvoll M, Stampfer MJ \& DIRECT Group. Dietary intervention to reverse carotid atherosclerosis. Circulation 2010121 1200-1208. (doi:10.1161/CIRCULATIONAHA.109. 879254)

21 Nissen SE, Nicholls SJ, Sipahi I, Libby P, Raichlen JS, Ballantyne CM, Davignon J, Erbel R, Fruchart JC, Tardif JC, Schoenhagen P, Crowe T, Cain V, Wolski K, Goormastic M, Tuzcu EM \& for the ASTEROID Investigators. Effect of very high-intensity statin therapy on regression of coronary atherosclerosis: the ASTEROID trial. Journal of the American Medical Association 2006295 1556-1565. (doi:10.1001/jama.295.13. jpc60002)

22 Nicholls SJ, Borgman M, Nissen SE, Raichlen JS, Ballantyne C, Barter P, Chapman MJ, Erbel R \& Libby P. Impact of statins on progression of atherosclerosis: rationale and design of SATURN (Study of Coronary Atheroma by Intravascular Ultrasound: effect of Rosuvastatin versus Atorvastatin). Current Medical Research and Opinion 201127 1119-1129. (doi:10.1185/03007995.2011. 570746)

23 Gryglewski RJ, Palmer RM \& Moncada S. Superoxide anion is involved in the breakdown of endothelium-derived vascular relaxing factor. Nature $1986 \mathbf{3 2 0} 454-456$. (doi:10.1038/ 320454a0)

24 Newman CB, Frisch KA, Rosenzweig B, Roubenoff R, Rey M, Kidder T, Kong Y, Pursnani A, Sedlis SP, Schwartzbard A \& Kleinberg DL. Moderate doses of hGH $(0.64 \mathrm{mg} / \mathrm{d})$ improve lipids but not cardiovascular function in GH-deficient adults with normal baseline cardiac function. Journal of Clinical Endocrinology and Metabolism 201196 122-132. (doi:10.1210/ jc.2010-1204)

25 Maison $\mathrm{P} \&$ Chanson P. Cardiac effects of growth hormone in adults with growth hormone deficiency: a meta-analysis. Circulation 2003 108 2648-2652. (doi:10.1161/01.CIR. 0000100720.01867.1D)

26 Leite NTF, Salvatori R, Alcântara MRS, Alcântara PRS, Oliveira CRP, Oliveira JLM, Anjos-Andrade FD, Farias MIT, Britto CTF, Nobrega LMA, Nascimento-Junior AC, Alves EO, Pereira RMC, Campos VC, Menezes M, Martinelli-Júnior CE \& 
Aguiar-Oliveira MH. Effects of depot growth hormone replacement on thyroid function and volume in adults with congenital isolated GH deficiency. Journal of Endocrinological Investigation 2012 (In press).

27 Van Thiel SW, Bax JJ, Biermasz NR, Holman ER, Poldermans D, Roelfsema F, Lamb HJ, Van der Wall EE, Smit JW, Romijn JA \& Pereira AM. Persistent diastolic dysfunction despite successful long-term octreotide treatment in acromegaly. European Journal of Endocrinology 2005153 231-238. (doi:10.1530/eje.1.01955)

28 Yuen KC, Frystyk J, White DK, Twickler TB, Koppeschaar HP, Harris PE, Fryklund L, Murgatroyd PR \& Dunger DB. Improvement in insulin sensitivity without concomitant changes in body composition and cardiovascular risk markers following fixed administration of a very low growth hormone $(\mathrm{GH})$ dose in adults with severe GH deficiency. Clinical Endocrinology 200563 428-436. (doi:10.1111/j.1365-2265.2005.02359.x)

Received 24 January 2012

Revised version received 25 February 2012

Accepted 12 March 2012 